\title{
Circulating Cell-Free DNA
}

National Cancer Institute

\section{Source}

National Cancer Institute. Circulating Cell-Free DNA. NCI Thesaurus. Code C128274.

DNA that is found in blood plasma and is not associated with cells in the circulation. 